\title{
Serial studies of autologous antibody reactivity to squamous cell carcinoma of the head and neck
}

\author{
Daniel R. Vlock ${ }^{1}$, Beth Arnold ${ }^{1}$, Jeannette Humpierres ${ }^{1}$, Donald R. Schwartz ${ }^{2}$, Shan R. Baker ${ }^{2}$, \\ Charles J. Krause ${ }^{2}$, Neil Swanson ${ }^{3}$, and Thomas E. Carey ${ }^{2}$ \\ ${ }_{1}$ Division of Medical Oncology, Pittsburgh Cancer Institute, University of Pittsburgh School of Medicine and the VA Medical Center, \\ Pittsburgh, PA 15240, USA \\ ${ }^{2}$ Department of Otolaryngology/Head and Neck Surgery, The University of Michigan School of Medicine, Ann Arbor, MI, 48109, USA \\ ${ }^{3}$ Department of Dermatology, The University of Michigan School of Medicine, Ann Arbor, MI, 48109, USA
}

Received 27 March 1991/Accepted 18 October 1991

\begin{abstract}
Summary. In previous studies we evaluated the incidence and specificity of autologous antibody reactivity against squamous cell carcinoma of the head and neck (SCCHN). We were able to demonstrate that autologous antibody reactivity is present in native sera but was usually of too low a titer to allow further analysis. Dissociation of immune complexes by acidification and ultrafiltration of serum augmented autologous antibody reactivity in nine out of nine autologous systems tested. Native antibody and antibody derived from immune complexes produced by the host and reactive with autologous tumor cells may be directed against physiologically relevant antigens. Therefore, correlations of antibody titers with clinical course may provide insight into the nature of the host response to cancer. In the present analysis, serological studies of six patients with SCCHN were performed with serum samples obtained over many months. Results of serial serological assays were correlated to tumor progression and clinical course. Fluctuations in autologous antibody reactivity were noted over time. In four cases, rises in autologous antibody titers preceded the clinical diagnosis of recurrence by several months. Drops in autologous antibody reactivity were noted in two cases following surgery or radiation therapy. In two cases of long-term survivors, no correlation between antibody reactivity and clinical course was noted. Specificity analysis of the six autologous systems demonstrated reactivity against autologous and allogeneic SCCHN as well as melanoma cell lines. These sera did not react with glioma, neuroblastoma, renal cell, breast, bladder and colon carcinoma cell lines nor with fetal calf serum, pooled lymphocytes, red blood cells and platelets. Autologous serial serological studies may provide a means by which to evaluate the host/tumor relationship in patients with SCCHN.
\end{abstract}

Offprint requests to: D. R. Vlock, Hematology/Oncology, VA Medical Center University Drive C, Pittsburgh, PA 15240, USA
Key words: Autologous antibodies - Head and neck squamous cell carcinoma - Immune complexes Host/tumor relationship

\section{Introduction}

The definition and characterization of tumor-associated antigens has been a major focus of tumor immunology for over two decades. Detection of these antigens has relied upon polyclonal xenogeneic and allogeneic antisera and more recently, murine monoclonal antibodies $[7,8,12]$. The majority of these investigations have been on melanoma and other tumors and there have been only a limited number of studies involving squamous cell carcinoma of the head and neck (SCCHN). As with other malignant diseases, monoclonal antibodies directed against SCCHN have been developed $[6,9,10]$; however, none has been shown to be absolutely restricted to tumor cells. An alternative approach to utilizing heteroantisera is to study the nature of the antibody response produced by the host. By doing so it may be possible to detect antigens not apparent to heteroantisera or monoclonal antibodies.

In previous work we examined the incidence and specificity of autologous antibodies in patients with melanoma $[3,11]$ and SCCHN $[4,23]$. As has been reported by others, these antibodies are usually of low incidence and titer. We demonstrated that, in a method described by Sjogren et al. [18], dissociation of immune complexes in melanoma and SCCHN $[11,23]$ augments autologous antibody reactivity in the majority of cases studied. Further studies in melanoma have shown correlations between autologous antibody titers, clinical course and prognosis [19-21]. In SCCHN native sera from eight patients were subjected to acid dissociation and ultrafiltration of sera. Prior to this, sera from only four of these patients were noted to have antibody reactivity against cultured autologous SCCHN cells as tested by protein A hemadsorption. After acid dissocia- 
tion/ultrafiltration, sera from all eight patients demonstrated enhanced IgG reactivity against SCCHN.

We have now extended our work in SCCHN to explore further the relationship between autologous immunity and the natural history of the disease. One way to pursue this is through serial studies of individual patients. Serial studies offer a unique means by which the correlations between clinical course and autologous antibody reactivity may be evaluated. By examining patients' sera at different times it may be possible to detect transient changes in antibody titer that are associated with the inception of recurrent disease or response to therapy. This paper represents the first study to explore the relationship between autologous antibody reactivity and clinical course in patients with squamous cell carcinoma. We report our findings in six patients with SCCHN followed over the course of their disease.

\section{Materials and methods}

\section{Cell lines}

SCCHN cell lines. The method described by Krause et al. [13] was developed in our laboratory for establishing SCCHN cell lines. Squamous cell carcinoma lines UM-SCC-8, $-9,-17,-21,-30$, and -36 were all derived from patients treated and followed in the Departments of Otolaryngology and Dermatology at the University of Michigan. The clinical course of each patient and the type of specimen used to establish each cell line is given in Results.

Non-SCCHN cell lines. Acquisition and maintenance of non-SCCHN cell lines have been previously reported [11]. For specificity analysis the following additional cell lines were used: melanoma cell lines Y-Mel $84: 420$ an Y-Mel $81: 710$ provided by Dr. John Kirkwood (University of Pittsburgh), neuroblastoma cell line SK-N-MC, glioma cell line and LN-18, fetal fibroblast cell line FF-110 supplied by Dr. Theresa Whiteside (University of Pittsburgh), and renal cell carcinoma cell lines 630D and IGR3 supplied by Dr. Byron Ballou (University of Pittsburgh); bladder carcinoma cell line HTB4 was kindly provided by Dr. Craig McCune (University of Rochester, School of Medicine, Rochester, N. Y.).

\section{Serological methods}

All patients participating in this study consented to provide serial serum specimens during clinic or hospital visits. Aliquots of serum were stored at $-70^{\circ} \mathrm{C}$.

Protein A hemadsorption. The protein A hemadsorption assay was performed after the method described by Pfreundschuh et al. [15]. Briefly, indicator cells for the protein A mixed hemadsorption tests were prepared by conjugating staphylococcal protein A (Pharmacia Fine Chemicals) to the surface of selected human blood group 0 Rh-positive red blood cells with $0.01 \% \mathrm{CrCl}_{3}$ at $\mathrm{pH} 5.0$. Indicator cells were washed twice in phosphate-buffered saline (PBS) plus $1 \%$ immunoglobulin-free fetal calf serum (Ig-free FCS) (Gibco) and resuspended for use in this medium. Target monolayers were seeded in micro-Terasaki assay plates and incubated with serial dilutions of autologous sera. After incubation of target cells with sera at $37^{\circ} \mathrm{C}$, wells were washed three times with PBS containing $2 \% \mathrm{Ig}$-free $\mathrm{FCS}$ at $37^{\circ} \mathrm{C}$ and $0.01 \mathrm{ml} 0.15 \%$ suspension of indicator cells was added to each well. Plates were washed two to four times with PBS $/ 2 \%$ Ig-free FCS after $45 \mathrm{~min}$, and positive cells defined as those with a $>50 \%$ erythrocyte rosette. The endpoint of the assay was the last well with $10 \%$ of positive target cells. All assays were performed in duplicate.
Absorption analysis. Absorptions were performed using a wide range of fresh, cryopreserved and cultured heterologous, allogeneic, and autologous cells. These were washed three times and for qualitative absorptions mixed at $1: 1 \mathrm{v} / \mathrm{v}\left(1 \times 10^{8} \mathrm{cells} / \mathrm{ml}\right.$ minimum $)$ with the serum to be tested $(0.1 \mathrm{ml}$, at a serum dilution two doublings below the endpoint of the titration for that serum). Absorptions were carried out for $30 \mathrm{~min}$ at $4^{\circ} \mathrm{C}$ then $30 \mathrm{~min}$ at $37^{\circ} \mathrm{C}$. Specimens were then centrifuged at $2000 \mathrm{rpm}$ for $20 \mathrm{~min}$ in a Sorvall RC3B refrigerated centrifuge. Supernatant serum was retested with an aliquot of control unabsorbed serum incubated in parallel, using protein A hemadsorption to assess the degree of specific antibody absorption.

\section{Immune complex dissociation}

The method, initially described by Sjogren et al. [18], was used to dissociate immune complexes. Briefly, a 60-ml ultrafiltration chamber and Amicon HP-30 membrane (Amicon Corporation, Danvers, Mass.) were used. A sample of $2-3 \mathrm{ml}$ prefiltered ( $0.45 \mu \mathrm{m}$, Millipore) serum was added to $50 \mathrm{ml}$ glycine/saline buffer, $0.1 \mathrm{M}, \mathrm{pH} 3.1$, in the ultrafiltration chamber. Ultrafiltration was performed at $4^{\circ} \mathrm{C}$ under $69 \mathrm{kPa}(10 \mathrm{lb}$ $\mathrm{in}^{-2}$ ) $\mathrm{N}_{2}$ until the original volume of the test solution was reached. This was repeated twice and the sample was then washed three times with $50 \mathrm{ml}$ PBS, and concentrated to the original volume of serum. The total time involved varied from $24 \mathrm{~h}$ to $48 \mathrm{~h}$ depending upon the serum used.

\section{Results}

\section{Immune complex dissociation of sera}

Our findings with eight autologous systems (UM-SCC-9, $-17,-21,-23,-24,-30,-35$, and -36 ) have previously been reported [23]. Serum from the patient from whom UMSCC-8 was obtained demonstrated a rise in autologous antibody titer from $1: 32$ in native serum to $1: 2048$ following immune complex dissociation.

\section{Specificity analysis}

To determine the distribution of expression of the antigens detected by autologous antibodies specificity analysis was performed against a variety malignant and non-malignant cells. Because of the limited amount of sera available all specificity analyses were performed with immune-complex-dissociated sera using a single high-titer serum. The results are summarized in Table 1. A similar range of reactivity was noted in all six autologous systems. In each case autologous antibody was absorbed by all seven SCCHN cell lines and two melanoma cell lines. No reactivity was noted against neuroblastoma, glioma, renal cell carcinoma, bladder carcinoma and colon carcinoma cell lines. In addition, no reactivity was noted against fetal fibroblasts, fetal calf serum, pooled lymphocytes, red blood cells and platelets.

\section{Serial autologous studies}

Serial studies were performed on six autologous systems (UM-SCC-8, -9, -17, -21, -30, and -36). Sera obtained at multiple intervals were tested before and after immune complex dissociation against autologous SCCHN by protein A hemadsorption. These results are shown in Figs. 1-6. The titer of antibody reactivity in serum speci- 
Table 1. Distribution of antigens defined by autologous antibody to squamous cell carcinomas of the head and neck ${ }^{\mathrm{a}}$

\begin{tabular}{|c|c|c|c|c|c|c|}
\hline \multirow[t]{2}{*}{ Target cell line ${ }^{\mathrm{a}}$} & \multicolumn{6}{|c|}{ Autologous system ${ }^{\mathrm{a}}$} \\
\hline & Um-SCC-8 & UM-SCC-9 & UM-SCC-17 & UM-SCC-21 & UM-SCC-30 & UM-SCC-36 \\
\hline \multicolumn{7}{|l|}{ Squamus cell carcinoma } \\
\hline UM-SCC-9 & + & + & + & + & + & + \\
\hline UM-SCC-17 & + & + & + & + & + & + \\
\hline UM-SCC-21 & + & + & + & + & + & + \\
\hline UM-SCC-30 & + & + & + & + & + & + \\
\hline \multicolumn{7}{|l|}{ Melanoma } \\
\hline Y-MEL $84: 420$ & + & + & + & + & + & + \\
\hline Y-MEL 81:710 & + & + & + & + & + & + \\
\hline \multicolumn{7}{|l|}{ Neuroblastoma } \\
\hline SK-N-MC & 0 & 0 & 0 & 0 & 0 & 0 \\
\hline \multicolumn{7}{|l|}{ Glioma } \\
\hline $630 \mathrm{D}$ & 0 & 0 & 0 & 0 & 0 & 0 \\
\hline IGR3 & 0 & 0 & 0 & 0 & 0 & 0 \\
\hline \multicolumn{7}{|l|}{ Breast carcinoma } \\
\hline MCF-7 & 0 & 0 & 0 & 0 & 0 & 0 \\
\hline \multicolumn{7}{|l|}{ Bladder carcinoma } \\
\hline HTB4 & 0 & 0 & 0 & 0 & 0 & 0 \\
\hline \multicolumn{7}{|l|}{ Colon carcinoma } \\
\hline HCT- 8 & 0 & 0 & 0 & 0 & 0 & 0 \\
\hline \multicolumn{7}{|l|}{ Fetal fibroblasts } \\
\hline FF-110 & 0 & 0 & 0 & 0 & 0 & 0 \\
\hline Fetal calf serum & 0 & 0 & 0 & 0 & 0 & 0 \\
\hline
\end{tabular}

a Sera from each autologous system were tested against the cells shown in this column both directly with protein A hemadsorption and by absorption with those cells and subsequent testing back against the appropriate autologous tumor cell line. + , Cross-reactivity of the autologous antibody with that cell line; 0 , no reactivity

mens taken at different times during the clinical course of these patients was correlated with clinical status. Antibody reactivity in separate sera varied in titer before and after acid immune complex dissociation.

Autologous system UM-SCC-8. Serial serum samples were obtained from the time of first treatment of this 70-year-old woman with leukoplakia and a T1N0M0 squamous cell carcinoma (SCC) of the left buccal mucosa. In the 6 months following the primary surgical excision, the patient had several persistent areas of leukoplakia and squamous papilloma, which were biopsied and found to have no tumor. However, an increase in antibody titers was noted in both native and immune-complex-dissociated sera (Fig. 1). This correlated with the development of a submandibular mass which, following resection, was felt to be a benign condition, sialoadenitis. In retrospect, however, there may have been tumor occluding the salivary duct that led to this condition because when the patient did develop clinically documented recurrent disease it was found in the left floor of the mouth near the opening of the duct. Anti- body titers subsequently fell, only to rise again prior to histologically confirmed tumor recurrence of the patient's SCCHN in a lesion in the anterior floor of the mouth. The patient was treated with surgical excision, external-beam radiotherapy and a cesium implant. Persistent disease involving the mandible necessitated further surgery. It was from this last operative procedure that the UM-SCC-8 tumor cell line was established. Autologous antibody titers fell after these interventions. Unfortunately the patient died as a result of a post-operative sepsis. The second rise in autologous antibody titers corresponded to the disease recurrence. The first rise in autologous antibody titers was not associated with proven disease recurrence unless there was occult SCCHN removed with the salivary gland resection that was not appreciated at the time of surgery.

Autologous system UM-SCC-9. This 72-year-old woman initially had a T2NOM0 SCC of the left side of the tongue that was treated with a partial glossectomy, radical neck dissection and radiation therapy 3 years prior to this study. Serial serum specimens were collected 1 month following 


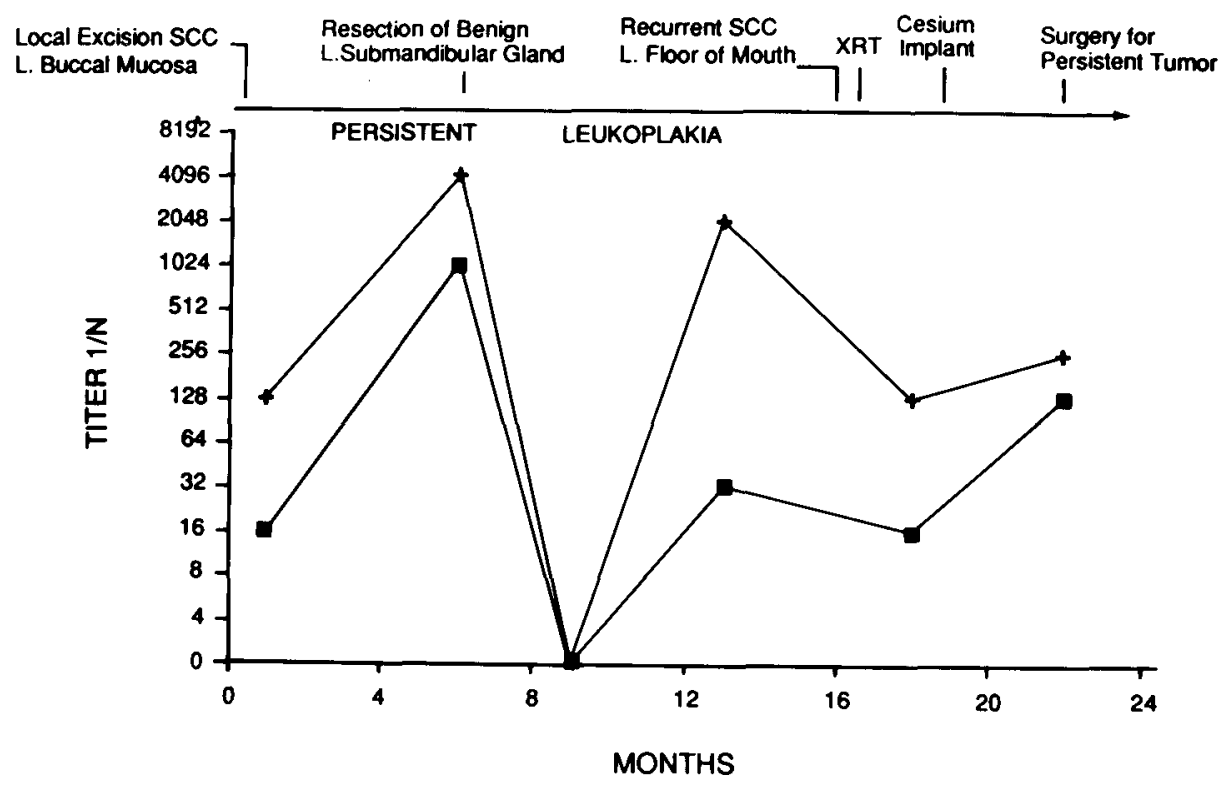

Fig. 1. Clinical time course for autologous system UM-SCC-8. The changes in autologous antibody titer according to the clinical time course of the patient who was the donor of UM-SCC-8. $\boldsymbol{m}$, Native serum antibody titers; + , immune complex dissociated serum antibody titers

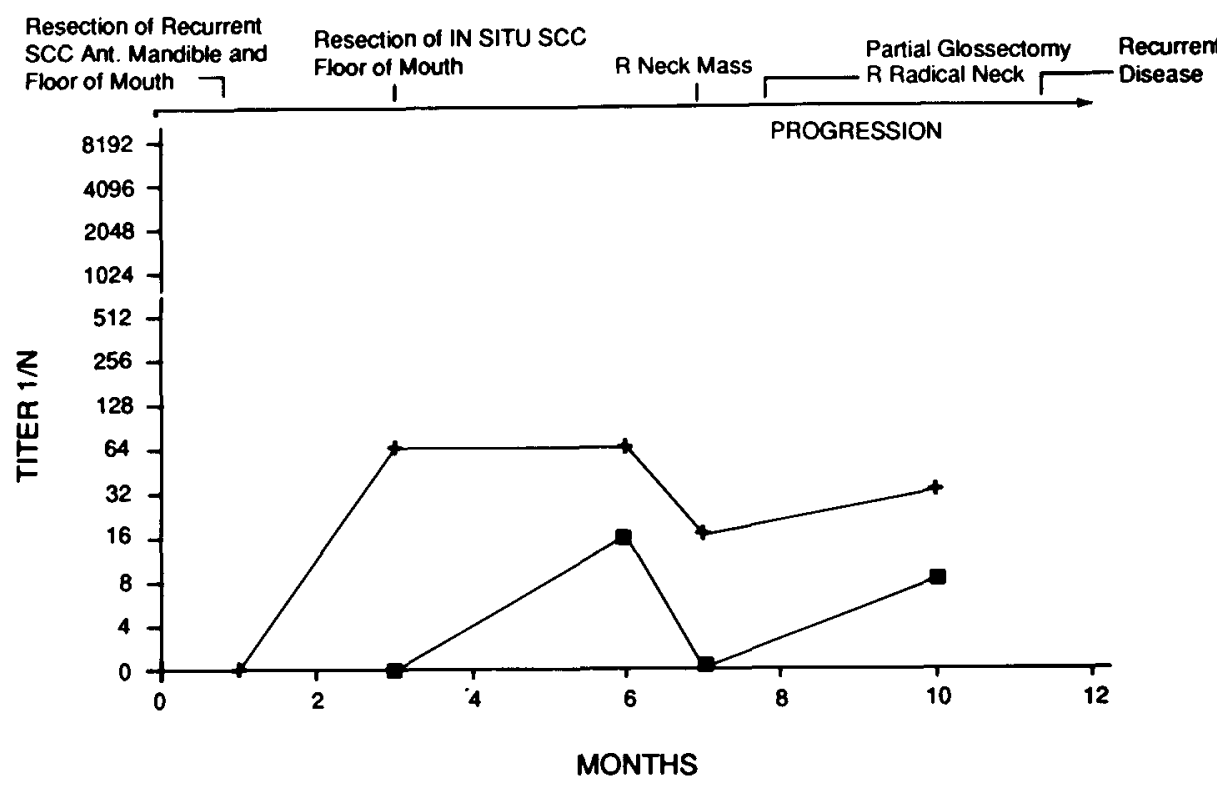

Fig. 2. Clinical time course for autologous system UM-SCC-9. The changes in autologous antibody titer according to the clinical time course of the patient who was the donor of UM-SCC-9. $\mathbf{m}$, Native serum antibody titers; +, immune complex dissociated serum antibody titers resection of recurrent cancer of the floor of mouth (Fig. 2). She later developed an in situ cancer of the tongue. Following surgical resection of these tumors a rise in autologous antibody reactivity was noted, first only in sera treated by acid dissociation/ultrafiltration and detected 5 months later in native sera as well. These increases in autologous antibody titers preceded clinical evidence of disease recurrence in the tongue and neck (Fig. 2). Surgical resection consisting of a further partial glossectomy and radical neck dissection was performed and the UM-SCC-9 cell line was established. Following this surgery both native and immune complex dissociated titers began to rise again, preceding the development of a local recurrence and metastasis.

Autologous system UM-SCC-17. This 48-year-old woman initially presented with a T1NOMO SCC of the left true vocal cord. She was treated with radiation but at the completion of her therapy was noted to have persistent disease and subsequently underwent a total laryngectomy and radical dissection of the left side of the neck. The UM-SCC-17 cell line was established from the primary tumor specimen [5]. Serial serum samples were obtained starting with the follow-up visits after surgery. Autologous antibody titers in native and immune complex dissociated sera were high for 20 months, fell over a 4-month interval and then began to rise gradually over the following year and a half. There were no changes in her clinical status during this time and she has remained free of disease to the present time, a period of more than 8.5 years (Fig. 3).

Autologous system UM-SCC-21. Twelve years after treatment of a basal cell carcinoma of the nasal dorsum this 65-year-old man presented with SCC of the nose, eyelid 


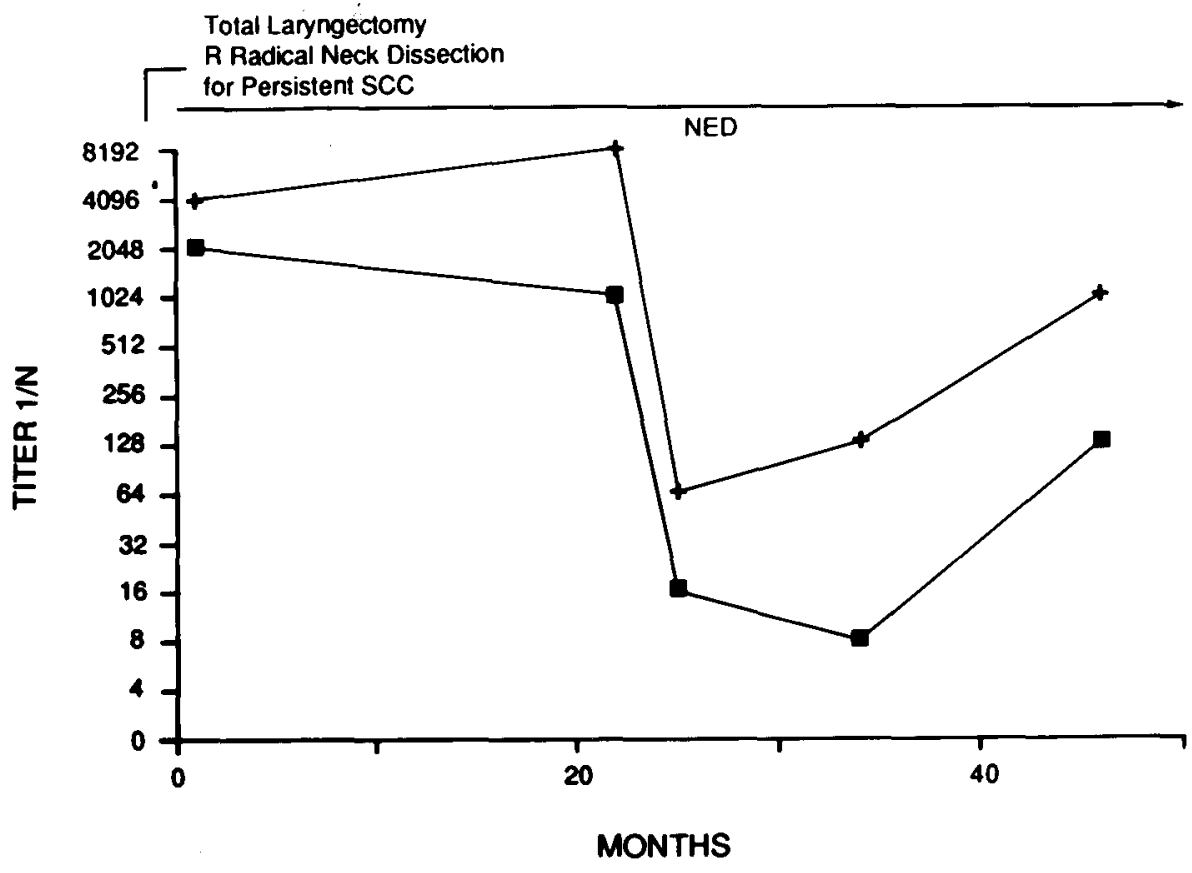

Fig. 3. Clinical time course for autologous system UM-SCC-17. The changes in autologous antibody titer according to the clinical time course of the patient who was the donor of UM-SCC-17. , Native serum antibody titers; + , immune complex dissociated serum antibody titers. $N E D$, no evidence of disease

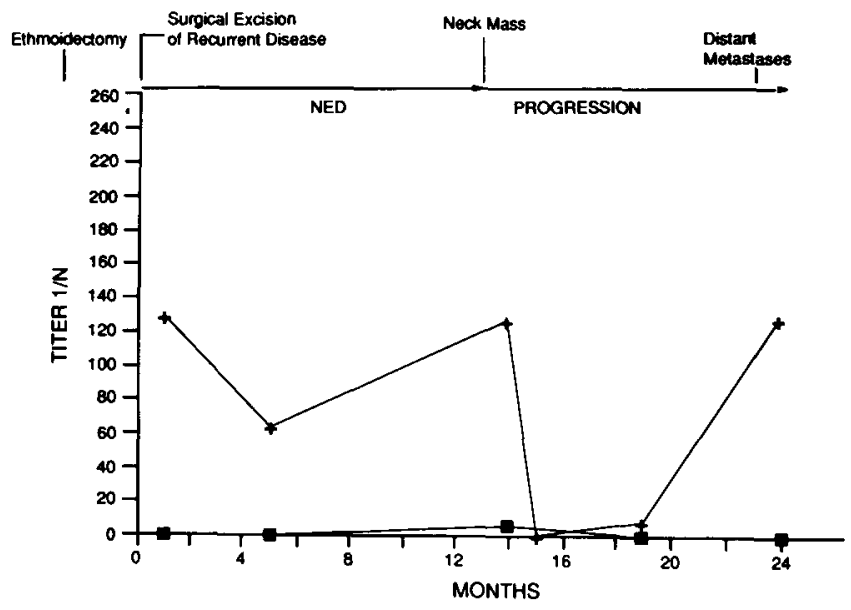

Fig. 4. Clinical time course for autologous system UM-SCC-21. The changes in autologous antibody titer according to the clinical time course of the patient who was the donor of UM-SCC-21. $\mathbf{m}$, Native serum antibody titers; + , immune complex dissociated serum antibody titers

and right medial canthus. The lesion required resection of the ethmoid bone and a skin graft followed by radiotherapy. He subsequently developed a local recurrence in the ethmoid sinus. This was resected with a right radical ethmoidectomy. The UM-SCC-21A cell line was established from this specimen and was used to test the sera. A recurrent tumor was resected from the superior aspect of the resection site 4 months later. Serial serum specimens were obtained starting at that point (Fig. 4). He was clinically free of disease for 14 months until a mass positive for SCC developed in the left side of the neck, which was resected and radiated. He remained clinically free of disease for 10 months until he developed a pathological fracture of the right humerus, which was treated with surgical excision and internal fixation. The patient's disease continued to progress slowly with spread of his tumor to the contralateral ethmoid sinus and medial canthus 4 and 9 months later respectively. The patient continued to develop additional distant metastases over the next 3 years and he died of progressive disease 5 years after the diagnosis of SCC. Antibody titers in immune complex dissociated sera were elevated during most of his clinical course. Two drops in autologous antibody titers were noted, one following treatment of his neck mass and the second following the left ethmoidectomy for recurrent disease. The final rise in autologous antibody titers paralleled the development of distant metastases.

Autologous system UM-SCC-30. This 53-year-old woman presented with a T3N1M0 SCC of the right pyriform sinus. Her clinical course is illustrated in Fig. 5. She was initially treated with two courses of chemotherapy followed by laryngectomy, radical neck dissection and radiation. The cell line was established from the primary tumor specimen and sera were obtained starting shortly after diagnosis while she was receiving chemotherapy. Five months after diagnosis she reported pain and dysphagia. Induration of the base of the tongue was noted but no evidence of tumor was found at biopsy. Histological confirmation of recurrent disease was made 2 months later when positive bronchial cytologies and progressive induration of the base of the tongue were noted. She died of progressive disease 11 months from the first diagnosis. Autologous antibody titers in immune complex dissociated sera showed a progressive rise (beginning in month 5) that preceded the diagnosis of recurrent cancer by several months. Antibody reactivity in native sera became detectable much later in the course of her disease.

Autologous system UM-SCC-36. This 46-year-old man with T2N0M0 SCC of the larynx and false vocal cord was treated with a supraglottic laryngectomy and radical dis- 


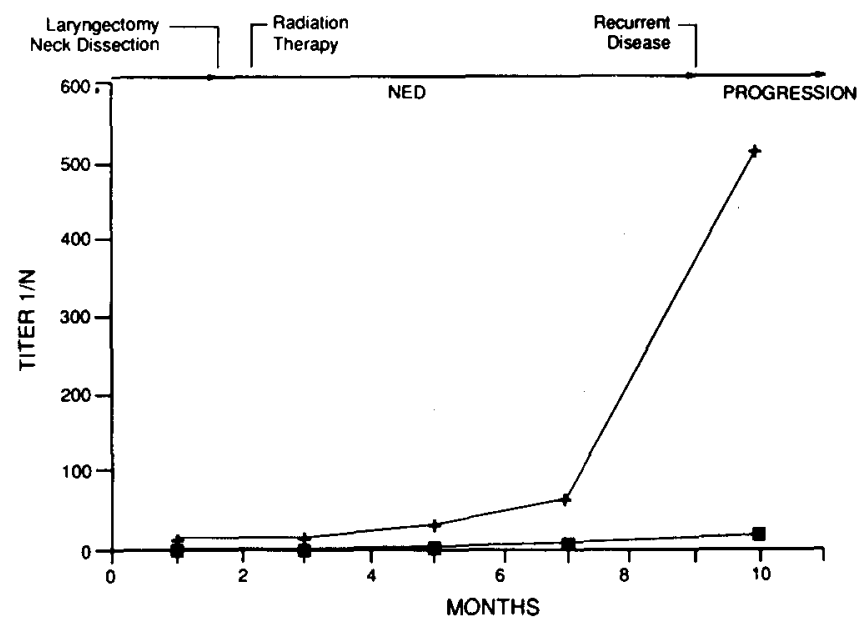

Fig. 5. Clinical time course for autologous system UM-SCC-30. The changes in autologous antibody titer according to the clinical time course of the patient who was the donor of UM-SCC-30. $\mathbf{a}$, Native serum antibody titers; + , immune complex dissociated serum antibody titers

section of the right side of the neck. The UM-SCC-36 cell line was established from the larynx tumor specimen. Collection of serial serum samples was begun 1 month following surgery. Autologous antibody reactivity was detectable in both native and immune complex dissociated sera. Titers did not change appreciably over 20 months, during which time the patient was clinically free of disease (Fig. 6). During this time the patient underwent exploration and drainage of an external fistula and abscess, which was not felt to be indicative of recurrent disease. Autologous antibody titers were not affected by that episode. The patient is still free of disease 5 years later.

\section{Discussion}

In a previous study, we evaluated the incidence and specificity of autologous antibody to SCCHN in both native and immune-complex-dissociated sera [23]. Our results were similar to findings noted in other tumor systems in that autologous antibody reactivity is present in native sera but is usually of too low a titer to permit further evaluation. We further noted that dissociation of immune complexes, as initially reported by Sjogren et al. [18], resulted in higher antibody reactivity in treated sera and allowed further evaluation of the host immune response. This report expands our previous experience to a total of nine SCCHN autologous systems. In all cases autologous antibody reactivity was noted to be enhanced following immune complex dissociation. Our findings suggest that antibody directed against autologous tumor cell surface antigens is present in a masked form in the sera of the majority of patients with SCCHN.

We have followed autologous antibody reactivity serially in six patients to determine the relationship between autologous antibody titers and clinical outcome. It appears that autologous antibody reactivity to SCCHN does correlate with clinical course, extending previous observations

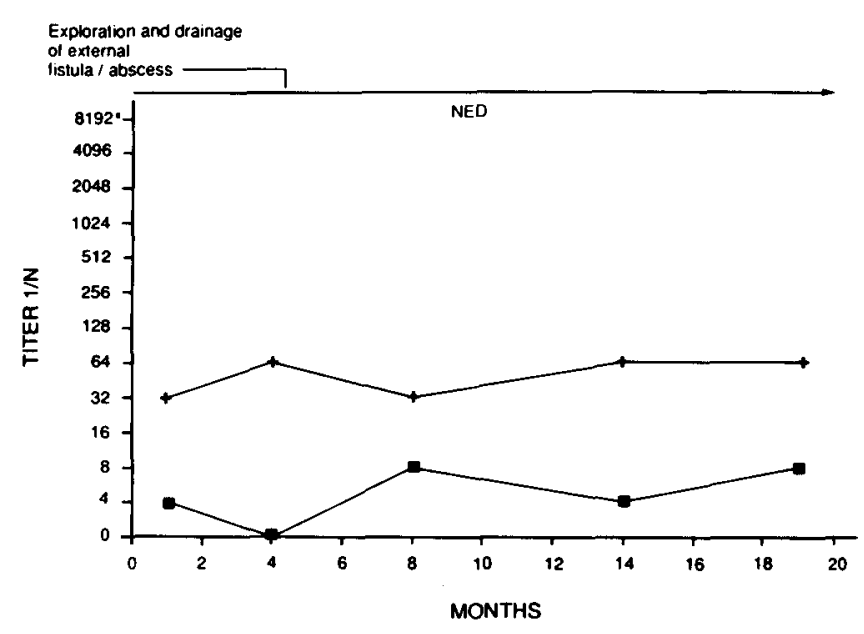

Fig. 6. Clinical time course for autologous system UM-SCC-36. The changes in autologous antibody titer according to the clinical time course of the patient who was the donor of UM-SCC-36. $\mathbf{m}$, Native serum antibody titers; + , immune complex dissociated serum antibody titers

made in melanoma [3]. In four of the six autologous systems analyzed there were rises in autologous antibody reactivity that preceded the diagnosis of recurrence by 1 or more months. In UM-SCC-8, -9, -21 and -30 (Figs. 1, 2, 4 and 5) autologous antibody titers in native and dissociated sera began to rise in advance of the diagnosis of recurrent disease. The relationship between a rise in autologous antibody titer and recurrence is most clearly seen in UM-SCC30 . In that case the rise in autologous antibody titers preceded by 4 months the diagnosis of recurrence. Autologous antibody titers in acid-dissociated sera rose from $1: 4$ to a peak of $1: 512$. Native autologous antibody titers did not rise as dramatically but were still noted to increase slightly above baseline prior to the diagnosis of recurrence.

Drops in autologous antibody titers were also noted to correlate with clinical course. In UM-SCC- 8 decreases in autologous antibody titer occurred following surgery or radiation. A similar decrease in antibody titer was seen in UM-SCC-21 following resection of a recurrent neck mass. As the drops in antibody titer occurred following local interventions they might be indicative of a reduction in tumor burden. In UM-SCC-8, the initial rise in native and dissociated antibody titers coincided with the development of a submandibular mass (Fig. 1). On resection the mass was noted to be a benign submandibular gland. The relationship between autologous antibody titers and this benign mass is unclear. It may be that the submandibular mass contained an occult focus of SCC that was not appreciated and its removal eliminated the stimulus for antibody production. Alternatively, it is possible that a decline in antibody titer may occur following any surgical intervention. No changes in autologous antibody titers were noted following chemotherapy (UM-SCC-30) or the development of an abscess (UM-SCC-36). The absence of any effect of chemotherapy on autologous antibody titers is consistent with previous observations we made in melanoma [19].

In two cases increases in antibody titers did not appear to correlate with clinical course. In both cases (UM-SCC- 
17 and UM-SCC-36), the patients have been long-term survivors and are alive and clinically free of disease at this time. In the case of UM-SCC-17 (Fig. 3) both native and dissociated autologous antibody titers were high during the 2 first postoperative years. The titers then fell with no apparent change in the patient's clinical course and then began to rise again, also without a change in clinical status, 26 months following resection of her tumor. While the nature of this patient's disease (i. e. recurrence immediately after radiotherapy and extension through the laryngeal cartilage into the adjacent soft tissue) makes a recurrence very likely, she has remained free of disease for more than 7 years. In the case of UM-SCC-36 there was also no clear association of antibody titer with clinical course. Autologous antibody titers were relatively constant over a 2-year period following surgery. This case is reminiscent of the AH/SK-MEL-13 system analyzed by Shiku et al. [16]. In that system autologous antibody titers did not change over time nor did the disease recur [2].

The primary impetus for these studies has been the observation that patients with SCCHN and other malignancies produce an antibody directed against their own tumor $[11,15,24]$. Because the antigens detected by these antibodies are, by definition, immunogenic to the host, further analysis is of interest. It is premature to state that these observations can be extrapolated into a clinically relevant assay. Two instances were noted in which antibody titers did not correlate with clinical course. It is intriguing that these two cases occurred in long-term survivors and suggests that other factors may be involved. Studies involving larger numbers of patients may help resolve this. However, the fact that rises and falls in autologous antibody reactivity could, in some instances, be correlated with the clinical course confirms studies performed in a separate tumor system [19] and is the first time this observation has been made in squamous cell carcinoma.

The specificity analysis performed on the six autologous systems reported here indicated that the antigen(s) being detected after acid dissociation/ultrafiltration have an identical distribution. Antibody reactivity could be absorbed by seven of seven SCCHN cell lines and two of two melanoma cell lines. No reactivity could be detected by absorption with other neoplastic and normal cells. This distribution of reactivity is consistent with a class II tumorassociated antigen as described by Shiku et al. $[16,17]$ in studies of melanoma (those which are shared among tumors of a similar histotype or ontogeny and infrequently found in non-neoplastic cells). The cross-reactivity with melanoma cells, seen in the present studies, is noteworthy. In previous studies of melanoma and SCCHN patients we have noted a similar range of antibody reactivity [21-23]. While specificity analysis of the antigen detected by autologous antibody allows for determination of the distribution of the antigen, it is, at best, limited. A major drawback in this approach is that it seeks to define a "null hypothesis". It can never be entirely proven that the antigen described will not be found on an untested cell line. Determination of the nature of the antigens detected by autologous antibody will have to await ongoing immunochemical analysis.

The nature of the relationship between the autologous antibody response and the host/tumor interaction remains to be determined. It is unknown whether the antigens and antibodies detected in this study are an indicator of the host's response to malignant cells or are somehow involved in the modulation of that response. Immune complexes and tumor-associated antigens have been implicated in immunosuppression $[1,14]$. These results demonstrate that serial autologous antibody studies can be correlated with clinical course and may provide a means by which the physiological relevance of the autologous immune response to malignant disease can be studied.

Acknowledgements. The authors wish to thank Dr. Barry Solomon, vice president for research of W. R. Grace \& Co. for technical advice and assistance. This study was in part supported by USPHS grants CA 28564 and CA 49708. Dr. Carey is the recipient of USPHS Research Career Development Award CA-00621 from NIH-NCI.

\section{References}

1. Baldwin RW, Robbins RA (1976) Factors interfering with immunological rejection of tumours. Br Med Bull 32: 118

2. Carey TE (1982) Immunologic aspects of melanoma. CRC Crit Rev Clin Lab Sci 18: 141

3. Carey TE, Lloyd KO, Houghton AN, Oettgen HF, Old LJ (1979) AU cell-surface antigen of human malignant melanoma. Solubilization and partial characterization. Proc Natl Acad Sci USA 76: 2898

4. Carey TE, Kimmel KA, Schwartz DR, Richter DE, Baker SR, Krause CJ (1983) Antibodies to human squamous cell carcinoma. Otolaryngol Head Neck Surg 91: 482

5. Carey TE, VanDyke DL, Worsham MJ, Bradford CR, Babu VR, Schwartz DR, Hsu S, Baker SR (1989) Characterization of laryngeal primary and metastatic squamous cell carcinoma cell lines UM-SCC17A and 17B. Cancer Res 49:6098

6. Eskinazi DP, Molinaro GA, Abermayor E, Martin SE, Zighelboim J (1985) Monoclonal antibodies against squamous cell carcinoma. Oral Surg Oral Med Oral Pathol 60: 377

7. Gupta RK, Silver HKB, Reisfeld RA, Morton DL (1979) Isolation and immunochemical characterization of antibodies from the sera of cancer patients which are reactive against human melanoma cell membranes by affinity chromatography. Cancer Res 39: 1683

8. Hellstrom I, Horn D, Linsley P, Brown JP, Brankovan V, Hellstrom KE (1986) Monoclonal mouse antibodies raised against human lung carcinoma. Cancer Res 46: 3917

9. Kimmel KA, Carey TE (1983) Altered expression in squamous cell carcinoma cells of an orientation restricted epithelial antigen detected by monoclonal antibody A9. Cancer Res 46: 3614

10. Kimmel KA, Carey TE, Judd WJ, McClatchey KD (1986) Monoclonal antibody $\mathrm{G} 10$ to a common antigen of human squamous cell carcinoma: Binding of the antibody to the $\mathrm{H}$ type 2 blood group determinant. J Natl Cancer Inst 76: 9

11. Kirkwood JM, Vlock DR (1984) Augmentation of autologous antibody to human melanoma following acid dissociation and ultrafiltration of serum. Cancer Res 44: 4177

12. Koprowski H, Steplewski Z, Herlyn D, Herlyn M (1978) Study of antibodies against human melanoma produced by somatic cell hybrids. Proc Natl Acad Sci USA 75: 3405

13. Krause CJ, Carey TE, Ott RW, Hubris C, McClatchey KD, Regezi JA (1981) Human squamous cell carcinoma. Establishment and characterization of new permanent cell lines. Arch Otolaryngol 107: 703

14. Nepom JT, Hellstrom I, Hellstrom KE (1983) Suppressor mechanisms of tumor immunity. Experientia 39: 235

15. Pfreundschuh M, Shiku H, Takahashi T, Ueda R, Ransohoff J, Oettgen HF, Old LJ (1978) Serological analysis of cell surface antigens of malignant human brain tumors. Proc Natl Acad Sci USA 75: 5122 
16. Shiku H, Takahashi T, Oettgen HF, Old LJ (1976) Cell surface antigens of human malignant melanoma. II. Serological typing with immune adherence assays and definition of two new surface antigens. J Exp Med 144: 873

17. Shiku H, Takahashi T, Carey TE et al. (1980) Definition of cell surface antigens in human malignant melanoma, astrocytoma and renal cancer by typing with autologous serum. In: Rosenberg SA (ed) Serological analysis of human cancer antigens. Academic Press, New York, $\mathrm{p} 305$

18. Sjogren HO, Hellstrom I, Bansal SC, Hellstrom KE (1971) Suggestive evidence that the "blocking factor antibodies" of tumor-bearing individuals may be antigen-antibody complexes. Proc Natl Acad Sci USA 68: 1372

19. Vlock DR, Kirkwood JM (1985) Serial studies of autologous antibody reactivity to melanoma: relationship to clinical course and circulating immune complexes. J Clin Invest 76: 849
20. Vlock DR, DerSimonian R, Kirkwood JM (1986) Prognostic role of antibody reactivity to melanoma. J Clin Invest 77: 1116

21. Vlock DR, Scalise D, Meglin N, Kirkwood JM (1988) Isolation and partial characterization of melanoma-associated antigens identified by autologous antibody. J Clin Invest 81: 1746

22. Vlock DR, Scalise D, Meglin N, Kirkwood JM, Ballou B (1988) Isolation and partial characterization of melanoma-associated-antigens identified by autologous antibody. J Clin Invest 81: 1746

23. Vlock DR, Scalise D, Schwartz DR, Richter DE, Krause CJ, Baker SR, Carey TE (1989) Incidence of serum antibody reactivity to autologous head and neck cancer cell lines and augmentation of antibody reactivity following acid dissociation and ultrafiltration. Cancer Res 49: 1361

24. Vlock DR, Scalise D, Schwartz DR, Richter DE, Krause CJ, Baker SR, Carey TE (1989) Incidence of serum antibody reactivity to autologous head and neck cancer cell lines and augmentation following acid dissociation and ultrafiltration. Cancer Res 49: 1361 